\title{
Study on Decision-Making of Reverse Recycling Medicine Quantity Under Manufacturer's Advertising Effort
}

\author{
Yue Tan ${ }^{\mathrm{a}, *}$, Ming Fang ${ }^{\mathrm{b}}$ \\ School of Management, Wuhan University of Technology, P.R.China, \\ a1078354526@qq.com, b1667701898@qq.com
}

\begin{abstract}
Keywords: household unwanted medicines, advertising efforts, government subsidies, the newsvendor problem, optimal recycling volume

Abstract: In recent years, the problem of medicine contamination has attracted more and more attention, especially the collection and disposal of unwanted medicines (UMs) in families has become an increasingly important research topic. This paper mainly studies the medicine recycling decision-making to maximize the profits of manufacturers. Based on the newsvendor problem and the pharmaceutical manufacturer as the research object, this study assumes a reverse recovery system including advertisement, incentive mechanism of integral exchange and government subsidies, and explores the relationship between medicine recovery and the three. Finally, according to the actual situation, it is proposed that increasing manufacturer's advertising investment cost and government subsidy appropriately and keeping a small conversion ratio of UMs are beneficial to improving manufacturer's expected earnings. Cooperation between manufacturers and retailers will also be considered in the future.
\end{abstract}

\section{Introduction}

In the past 20 years, prescription and over-the-counter medicines have been flooding people's lives. The World Health Organization believes that the use of unwanted medicines should always be considered drug waste (Gray, R et al., 1999)[1]. UMs includes a range of expired, unused, spilled, and contaminated medicines, vaccines, and serUMs that are no longer needed and need to be disposed of properly(WHO, 2014). As the number of personal consumption medicines increases, households may become the main source of drug contaminants (Ariffin Mariani et al., 2019)[2]. This phenomenon promotes discussion in all sectors of society on the best way to deal with unused or unwanted medicine recovery. Numerous studies have shown that treating pharmaceutical waste is to return them to the pharmacy or to recover the production site.

In recent years, the government has stepped up efforts to supervise drug recycling. The specific measures are to increase the penalties for not implementing drug recycling enterprises and increase the social welfare subsidies for manufacturers, so that the success rate of government intervention can be effectively improved, which is beneficial to promote government intervention in drug recycling reverse logistics chain.

The researchers studied the reverse logistics process of plastic waste (Xiaoyun Bing et al., 2014)[3], waste batteries (Jighyasu Gaur et al., 2017)[4], and used household appliances (Han Li et al., 2019)[5]. The results were not satisfactory. In the case of a general reverse supply chain, UMs management is quite challenging and difficult to implement. Therefore, related research is rare.

\section{Literature review}

As one of the traditional marketing communication tools, advertising stimulates consumers' purchasing behavior through persuasion and interest, thereby increasing the sales volume of products, and then achieving the purpose of improving profits, consolidating brand image and improving the performance of the entire supply chain. A large number of studies have focused on the benefits of advertising strategies for supply chain performance. Xu Minghui, Liu Wanxia and others found that the ingredient branding strategy can encourage manufacturers and suppliers to increase advertising investment, enable manufacturers to obtain higher advertising subsidies, and help to enhance the brand awareness of each member[6]. Therefore, in the reverse supply chain of drug recycling, manufacturers adopt advertising strategies to effectively improve their green image and promote recycling.

Although medicines can treat and prevent disease, they are now one of the new pollutants in the 
environment. Medicines are prone to accumulation and waste due to drug non-compliance, death, and drug changes. Discarded waste medicines are a serious threat to the social environment and economic construction. Governments have developed a series of guidelines and policies for the recycling and disposal of household waste medicines to reduce their environmental pollution.

As a recognized model in the public health field in the world, The government of Sweden manages and controls the research and development, production, sales and recycling of medicines. The customer returns the used medicines to the retailers, and the retailers transfer them to the designated units for disposal. This single-channel centralized mandatory control model greatly reduces the cost of drug recovery and improves the efficiency of drug recovery. The UK's Environmental Protection Act clearly states that producers of expired medicines have an obligation to ensure that the expired medicines produced are disposed of safely and properly. Special medicines should be treated in strict accordance with the prescribed procedures and recovered by designated recycling companies. France has passed the government legal coercive measures to hand over the drug recycling work to the enterprise, the government's main debt supervision and the punishment for the company's failure to fulfill the recycling responsibility. The US states have independently abandoned the drug recovery legislation, and finally sent it to the appropriate agencies for destruction under the supervision of the FDA. Eman Abahussain et al. pointed out that the accumulation of unused medicines leads to waste of medicines and loss of economic resources. Although the problem of unused medicines is clearly defined worldwide, there are still barriers to reducing medicine waste. Developed countries have developed many mitigation measures, including reducing waste by pharmacists, prescribers and the public. While various mitigation strategies (such as smart medicine cabinets) to reduce drug waste have emerged, there is still a need for joint work between public, healthcare providers, and various government and private organizations to adequately address drug waste issues (Makki Mutaseim Et al., 2019)[7].

\section{Problem Description and Research Purposes}

This study assumes a reverse logistics system that includes advertising, point exchange, and social welfare incentives. The supply chain consists of pharmaceutical manufacturers and consumers, and manufacturers directly target consumers. The government subsidizes the manufacturer's recycling of UMs, and when the manufacturer's daily average drug recovery is greater than the average daily drug sales, additional subsidies per unit for multi-recycled medicines are provided by the government to encourage manufacturer's advertising efforts.

Residents return UMs to the manufacturer's acceptance point and can be used to obtain points for purchasing new medicines, returning to the manufacturer's discretion based on the ratio. The kilogram of um can be recorded as 20 points, equal to $\$ 0.2$, with a ratio of 50:1. If a resident wants to buy a new drug for $\$ 1$, he can accumulate 50 points $(5 \mathrm{~kg})$ for a new drug, or spend 5 points for a $10 \%$ discount. Due to financial incentives, point exchange incentives can stimulate the collection of UMs. Government policy support allows manufacturers to profit from government subsidies. The manufacturer then processes the collected UMs. The specific treatment depends on the characteristics of the collected UMs and the policies of the local government.

In order to test the optimal recovery of the manufacturer under the social welfare incentives of the government for reverse recycling of the manufacturer, this paper establishes the manufacturer's income function. According to the practice of pharmacy collection in countries around the world, a the Newsvendor Problem was established. Through the establishment of models and data analysis, it is expected to solve the following problems:

(1) Is it beneficial to use social welfare incentives for advertising efforts in manufacture rs' reversely recycle medicines?

(2) Under the guidance of the government welfare policy, does the manufacturer have an average daily optimal drug recovery to maximize its own income? 


\section{Problem Assumptions and Parameters}

Hypothesis 1: The proposed reverse logistics system consists of manufacturers and consumers. In the long-term supply chain, manufacturers produce medicines and then sell them to consumers through the medicine market. In the reverse supply chain, the government uses welfare subsidies to provide manufacturers with social welfare incentives, manufacturers recycle UMs, and consumers provide UMs and reward points for rewards.

Hypothesis 2: In order to simplify the model, it is assumed that the medicine on sale can be regarded as the average value of the medicine in reality. And suppose that in the short term, the sales price of medicines in the reverse supply chain is constant (the price of medicines does not change often, because the drug market is a completely competitive market, and consumers who buy medicines are not price-sensitive consumers.). In this case, the relevant parameters are also stable. Many scholars also assume that prices are constant in research, such as Huang and Li (2001)[8] and Zhang et al. (2013)[9]. The amount of drug recovery in this paper is positively influenced by the advertising efforts and point exchange activities that manufacturers make to collect UMs, because this paper believes that these activities are beneficial to the government's policy of recycling households without medicines, and can also improve the Green Image of Manufacturers. Therefore, in the case of constant price, the demand for new medicines is set to a fixed value, and the amount of drug recovery is set as a variable. The amount of drug recovery is affected by the degree of advertising efforts in the collection activities, the proportion of incentives for exchange of points, and social welfare. No consideration is given to surplus units or shortages, so there is a definite demand for medicines.

Throughout the research process, the greater the amount of drug recovery, the greater the advertising efforts of the manufacturer, and the greater the cost of the corresponding advertising efforts. But once the manufacturer's average daily drug recovery is greater than the average daily drug sales, the government Multi-recycled medicines are subject to additional subsidies per unit, resulting in lower manufacturer costs. We take the advertising cost per unit of drug recycling by manufacturers and the weight of collected UMs as the measurement unit, but it can also be adjusted on a case-by-case basis. For example, you can determine the unit based on the number of collected UMs. The quantity of new medicines used for exchange is that the manufacturer announces a point exchange reward to the UMs head of household. The total weight of the collected UMs is linear with the manufacturer's advertising level and the point exchange incentive ratio. The relevant parameters and variables are shown in the table below.

Table 1 relevant parameters and variables

\begin{tabular}{|c|c|}
\hline Forward supply chain & Reverse supply chain \\
\hline $\mathrm{Q}_{\mathrm{f}}:$ Quantity of new medicines & $\mathrm{M}_{\mathrm{u}}$ : weight of collected UMs \\
\hline $\begin{array}{l}\text { D: The basic medications demand in the FSC } \\
\text { without advertising and points-exchange } \\
\text { incentive }\end{array}$ & $\begin{array}{l}\varphi \text { : Integral exchange incentive ratio from UMs to } \\
\text { New Medicines }\end{array}$ \\
\hline$\alpha_{0}$ :Customer's sensitivity to advertising effort & s: Government subsidy \\
\hline $\begin{array}{l}\beta_{0}: \text { Customer's sensitivity to point exchange } \\
\text { incentive ratio }\end{array}$ & $\mathrm{c}_{\mathrm{u}}$ :Unit cost for disposal and transportation of UMs \\
\hline $\begin{array}{l}\text { W: selling prices of manufacturers on the } \\
\text { market }\end{array}$ & I: Unit cost of advertising input to collect UMs \\
\hline $\begin{array}{l}\mathrm{c}_{\mathrm{m}} \text { :Unit cost of pharmaceutical products } \\
\text { produced by manufacturers }\end{array}$ & \multirow{3}{*}{$\begin{array}{l}\theta: \text { When } Q_{F}<Q_{P}, \text { government subsidies to } \\
\text { manufacturers are }\left(Q_{P}-Q_{F}\right) \theta\end{array}$} \\
\hline variable & \\
\hline$Q_{P}:$ Quantity & \\
\hline
\end{tabular}




\section{Model Construction}

Assume that the daily sales volume of the medicine is $Q_{F}$, because the recovery amount $Q_{P}$ is random, $Q_{P}$ can be less than $Q_{F}$, equal to $Q_{F}$ or greater than $Q_{F}$, causing the manufacturer's daily earnings random. So as the objective function of the optimization model, it should not be the daily income of the manufacturer, but the daily average income of the manufacturer who sells and recycles medicines for a long period of time (months, years). The average income, from the perspective of the law of large numbers of probability theory, is equivalent to the expected value of the manufacturer's daily income, hereinafter referred to as the average income.

$$
\pi_{m}=\sum_{Q_{p}=0}^{Q_{f}}\left[\left(w-c_{m}\right)\left(Q_{f}+Q_{p}\right)+\left(s-c_{u}\right) M_{u}-Q_{p} \cdot I-\pi_{m 0}\right] \cdot f\left(Q_{p}\right)+\sum_{Q_{p}=Q_{f}^{+1}}^{\infty}\left[\left(w-c_{m}\right)\left(Q_{f}+Q_{p}\right)+\left(s-c_{u}\right) M_{u}-Q_{p} \cdot I+\left(Q_{p}-Q_{p}\right) \theta-\pi_{m 0}\right] \cdot f\left(Q_{p}\right)
$$

$\pi_{\mathrm{m} 0}$ represents the profit when there is no collection activity. $\pi_{\mathrm{m} 0}=\left(\mathrm{w}-\mathrm{c}_{\mathrm{m}}\right) \mathrm{D}$

Usually $\mathrm{Q}_{\mathrm{f}}$ and $\mathrm{Q}_{\mathrm{p}}$ are quite large, and $\mathrm{Q}_{\mathrm{p}}$ is considered as a continuous variable to facilitate analysis and

Calculate, then the probability $f\left(Q_{p}\right)$ is converted into the probability density function $F\left(Q_{p}\right)$, and the formula becomes

$$
\pi_{m}=\int_{0}^{Q_{f}}\left[\left(w-c_{m}\right)\left(Q_{f}+Q_{p}\right)+\left(s-c_{u}\right) M_{u}-Q_{p} \cdot I-\pi_{m 0}\right] \cdot p\left(Q_{p}\right) d Q_{p}+\int_{Q_{f}}^{\infty}\left[\left(w-c_{m}\right)\left(Q_{f}+Q_{p}\right)+\left(s-c_{u}\right) M_{u}-Q_{p} \cdot I+\left(Q_{p}-Q_{f}\right) \theta-\pi_{m 0}\right] \cdot p\left(Q_{p}\right) d Q_{p}
$$

Then $\mathrm{d} \pi_{\mathrm{m}} / \mathrm{dQ}_{\mathrm{p}}=0$

Obtain $\left(2 \mathrm{D}+\alpha_{0} \mathrm{I}+\beta_{0} \varphi-2 \mathrm{Q}_{\mathrm{p}}\right) \theta \mathrm{F}\left(\mathrm{D}+\alpha_{0} \mathrm{I}+\beta_{0} \varphi-\mathrm{Q}_{\mathrm{p}}\right)=0$. According to the conditions known in this paper, $\theta>0, F\left(D+\alpha_{0} I+\beta_{0} \varphi-Q_{p}\right)>0$.

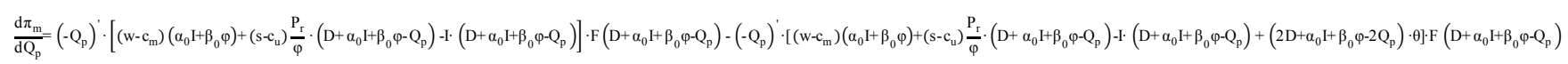

So $2 \mathrm{D}+\alpha_{0} \mathrm{I}+\beta_{0} \varphi-2 \mathrm{Q}_{\mathrm{p}}=0, \mathrm{Q}_{\mathrm{p}}=\left(2 \mathrm{D}+\alpha_{0} \mathrm{I}+\beta_{0} \varphi\right) / 2$

From the above, the manufacturer is encouraged by the government's efforts to advertise the reverse recycling of medicines. There is an average daily recovery $Q_{p}=\left(2 D+\alpha_{0} I+\beta_{0} \varphi\right) / 2$, which makes the largest manufacturer's daily average income. As a result, manufacturers can limit the amount of medicines recovered per day to maximize revenue.

\section{Data Analysis}

Assume that in the absence of advertising and points redemption rewards, the average daily demand for medicines is 100 . The profit of the manufacturer is 5 yuan per unit of medicines sold. $\mathrm{s}-\mathrm{C}_{\mathrm{u}}=1, \alpha_{0}=50, \beta_{0}=500, \mathrm{I}=10, \varphi=0.4, \mathrm{P}_{\mathrm{r}}=3, \theta=2, \mathrm{P}_{\mathrm{u}}=1, \mathrm{w}=2, \mathrm{~F}=4000$ 。

In order to make the variable identification model affect the daily average drug recovery and daily average earnings, the sensitivity analysis of the unit cost of manufacturer's recycling medicine advertising investment, the sensitivity analysis of the incentive ratio of integral exchange from UMs to new medicines, and the sensitivity analysis of the government's additional subsidies were discussed.

A. the sensitivity analysis of the unit cost of manufacturer's recycling medicine advertising investment

In order to study the relationship between the unit cost of manufacturer's recycling drug advertising investment and the optimal recovery and maximum expected return, we change the unit cost I of advertising investment in the above example with other parameters unchanged. 
Table 2 the change of relevant parameters

\begin{tabular}{|c|c|c|c|}
\hline $\mathrm{I}$ & $\pi_{\mathrm{m}}$ & $\mathrm{Q}$ & $\mathrm{Q}_{5}$ \\
\hline 1 & 2912.5 & 225 & 125 \\
\hline 3 & 3187.5 & 275 & 175 \\
\hline 5 & 3262.5 & 325 & 225 \\
\hline 7 & 3137.5 & 375 & 275 \\
\hline 10 & 2575 & 450 & 350 \\
\hline 20 & 2550 & 700 & 600 \\
\hline
\end{tabular}

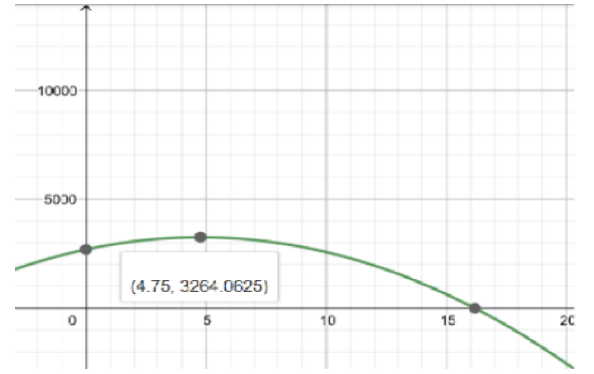

Figure $1 \pi_{\mathrm{m}}$ function curve for I

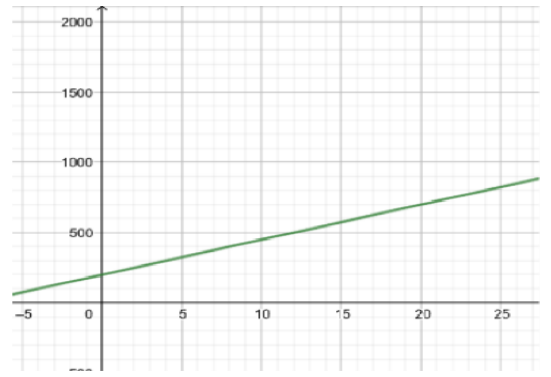

Figure $2 Q_{p}$ function curve for I

From the table we can see that when the advertising unit cost $\mathrm{I}$ is low, $\pi_{\mathrm{m}}$ increases as $\mathrm{I}$ increases. However, as I rise to $4.75, \pi_{\mathrm{m}}$ decreases as I increases, which is the result of excessive advertising cost per unit of household waste. When $\mathrm{I}$ is too high, $\pi_{\mathrm{m}}$ will no longer receive a profit or even a loss. The optimal recovery $\mathrm{Q}_{\mathrm{p}}$ increases with the increase of $\mathrm{I}$. During the medicine recycling process, manufacturers can increase the cost of advertising input to achieve higher returns.

B. the sensitivity analysis of the incentive ratio of integral exchange from UMs to new medicines

In order to study the relationship between the manufacturer's point redemption ratio and the optimal recovery and maximum expected return, we change the incentive ratio in the above example with other parameters unchanged.

Table 3 the change of relevant parameters

\begin{tabular}{|c|c|}
\hline$\varphi$ & $\pi_{m}$ \\
\hline 0.20 & 5200 \\
\hline 0.25 & 4150 \\
\hline 0.30 & 3450 \\
\hline 0.40 & 2575 \\
\hline 0.60 & 1700 \\
\hline$\infty$ & \\
\hline$\infty$ & \\
\hline$\infty$ & \\
\hline
\end{tabular}

Figure $3 \pi_{\mathrm{m}}$ function curve for $\varphi$

\begin{tabular}{|c|c|}
\hline $\mathrm{Q}$ & $\mathrm{Q}_{\mathrm{f}}$ \\
\hline 400 & 300 \\
\hline 12.5 & 312.5 \\
\hline 425 & 325 \\
\hline 450 & 350 \\
\hline 500 & 400 \\
\hline
\end{tabular}

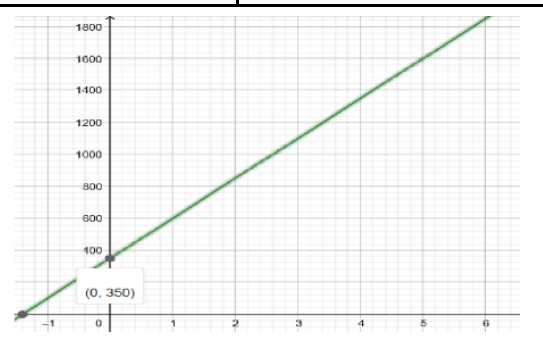

Figure $4 \mathrm{Q}_{\mathrm{p}}$ function curve for $\varphi$

It can be seen from the table that as $\varphi$ increases, $\pi_{\mathrm{m}}$ gradually decreases and tends to zero, and the optimal recovery amount $\mathrm{Q}_{\mathrm{p}}$ increase. Therefore, in the medicine recycling process, the manufacturer should maintain a small UMs exchange ratio to maintain a higher return. C. the sensitivity analysis of the government's additional subsidies

In order to study the relationship between government subsidies and optimal recycling and maximum expected returns, we change the government's additional subsidies in the above example with other parameters unchanged.

Table 4 the change of relevant parameters

\begin{tabular}{|c|c|c|c|}
\hline$\theta$ & $\pi_{\mathrm{m}}$ & $\mathrm{Q}$ & $\mathrm{Q}_{\text {f }}$ \\
\hline 1 & 2425 & 450 & 350 \\
\hline 3 & 2625 & 450 & 350 \\
\hline 5 & 2825 & 450 & 350 \\
\hline 7 & 3025 & 450 & 350 \\
\hline 10 & 3325 & 450 & 350 \\
\hline
\end{tabular}




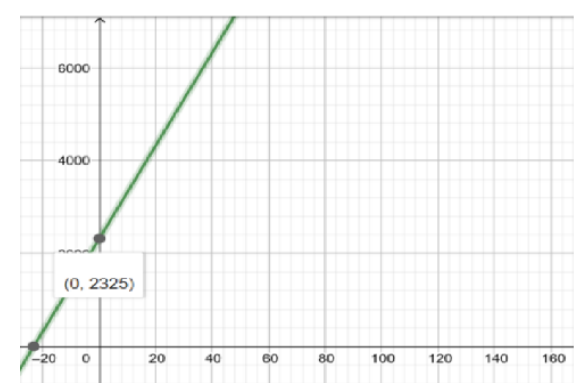

Figure $5 \pi_{\mathrm{m}}$ function curve for $\theta$

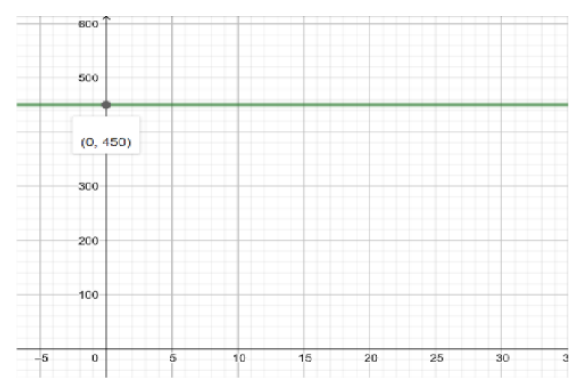

Figure $6 \mathrm{Q}_{\mathrm{p}}$ function curve for $\theta$

It can be seen from the figure that there is a linear positive correlation between $\pi_{\mathrm{m}}$ and $\theta$, and $\pi_{\mathrm{m}}$ increases with increasing of $\theta$. When $\theta$ changes, $Q_{p}$ is constant. The more subsidies government gives, the greater the profit of the manufacturer is.

\section{Conclusion}

Aiming at the optimal recovery of manufacturers in the reverse recovery system including advertisement, incentive mechanism of integral exchange and government subsid ies, this paper studies the manufacturer's newsvendor problem from the perspective of management, gives the corresponding manufacturer's optimal medicine recovery decision- making, and further studies the relevant parameters for the optimal recovery. The results show that, under the guidance of government welfare policy, manufacturers have an average daily optimal medicine recovery. Increasing manufacturer's advertising investment cost and government subsidy appropriately and keeping a small proportion of UMs exchange rate are beneficial to improving manufacturer's expected earnings. Cooperation between manufacturers and retailers will also be considered in the future.

\section{References}

[1]Gray, R. Guidelines for Safe Disposal of Unwanted Pharmaceuticals in and after Emergencies; World Health Organization: Geneva, Switzerland, 1999; p. 31.

[2] Ariffin Mariani,Zakili Tengku Sahbanun Tengku. Household Pharmaceutical Waste Disposal in Selangor, Malaysia-Policy, Public Perception, and Current Practices.[J]. Environmental management,2019,64(4).

[3]Han Li, Wei Jin, Wang Wan. Statistical analysis of research literature on reverse logistics of waste household appliances in China from 2004 to 2018 [J]. Logistics Science and Technology, 2019, 42 (04): 57-59.

[4]Xiaoyun Bing,Jacqueline M. Bloemhof-Ruwaard,Jack G. A. J. Vorst. Sustainable reverse logistics network design for household plastic waste[J]. Flexible Services and Manufacturing Journal,2014,26(1-2).

[5]Jighyasu Gaur,Mehdi Amini,A.K. Rao. Closed-loop supply chain configuration for new and reconditioned products: An integrated optimization model[J]. Omega,2017,66.

[6] Xu Minghui, Liu Wanxia. Research on dynamic cooperative advertising based on factor brand strategy in the competitive environment of manufacturers [J].Journal of Management Engineering, 2019,33(03): 162-169.

[7]Makki Mutaseim, Hassali Mohamed Azmi,Awaisu Ahmed,Hashmi Furqan. The Prevalence of Unused Medications in Homes.[J]. Pharmacy (Basel, Switzerland),2019,7(2).

[8] Huang, Z.M., Li, S.X., 2001. Co-op advertising models in manufacturer-retailer supply chains: a game theory approach. Eur. J. Oper. Res. 135, 527-544.

[9] Zhang, J., Gou, Q.L., Liang, L., Huang, Z.M., 2013. Supply chain coordination through cooperative advertising with reference price effect. Omega Int. J. Manag. Sci. 41,345-353. 